Author(s): Zhang, Peng \& Väinölä, Hele \& Istratov, Andrei A. \& Weber, Eicke R.

Title: $\quad$ Thermal stability of internal gettering of iron in silicon and its impact on optimization of gettering

Year: 2003

Version: Final published version

Please cite the original version:

Zhang, Peng \& Väinölä, Hele \& Istratov, Andrei A. \& Weber, Eicke R. 2003. Thermal stability of internal gettering of iron in silicon and its impact on optimization of gettering. Applied Physics Letters. P. 3. 0003-6951 (printed). DOI: 10.1063/1.1630158.

Note: $\quad$ Copyright 2003 American Institute of Physics. This article may be downloaded for personal use only. Any other use requires prior permission of the author and the American Institute of Physics.

http://scitation.aip.org/content/aip/journal/apl

All material supplied via Aaltodoc is protected by copyright and other intellectual property rights, and duplication or sale of all or part of any of the repository collections is not permitted, except that material may be duplicated by you for your research use or educational purposes in electronic or print form. You must obtain permission for any other use. Electronic or print copies may not be offered, whether for sale or otherwise to anyone who is not an authorised user. 


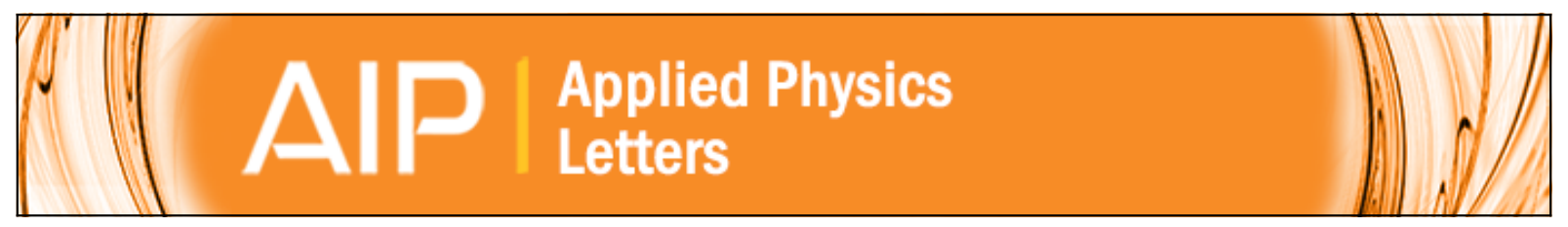

Thermal stability of internal gettering of iron in silicon and its impact on optimization of gettering

Peng Zhang, Hele Väinölä, Andrei A. Istratov, and Eicke R. Weber

Citation: Applied Physics Letters 83, 4324 (2003); doi: 10.1063/1.1630158

View online: http://dx.doi.org/10.1063/1.1630158

View Table of Contents: http://scitation.aip.org/content/aip/journal/apl/83/21?ver=pdfcov

Published by the AIP Publishing

\section{Articles you may be interested in}

Lattice location and thermal stability of implanted nickel in silicon studied by on-line emission channeling J. Appl. Phys. 115, 023504 (2014); 10.1063/1.4861142

Investigation of iron impurity gettering at dislocations in a SiGe/Si heterostructure

J. Appl. Phys. 105, 073712 (2009); 10.1063/1.3093912

Internal gettering of iron in multicrystalline silicon at low temperature

Appl. Phys. Lett. 93, 152108 (2008); 10.1063/1.2987521

Impact of the end of range damage from low energy Ge preamorphizing implants on the thermal stability of shallow boron profiles

J. Appl. Phys. 96, 4939 (2004); 10.1063/1.1776624

Lateral gettering of iron by cavities induced by helium implantation in silicon

J. Appl. Phys. 88, 5000 (2000); 10.1063/1.1315328
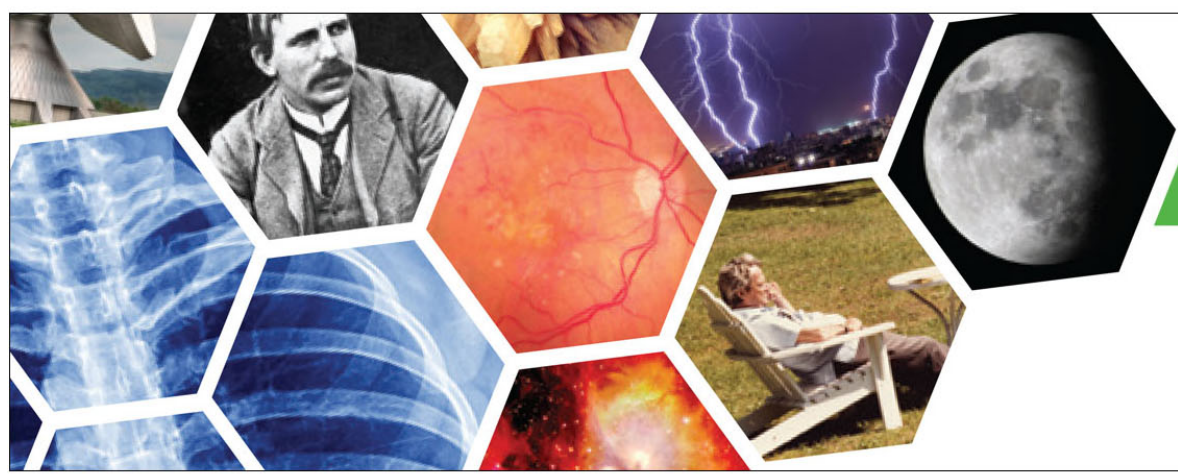

\section{SUBSCRIBE TO \\ physics today}




\title{
Thermal stability of internal gettering of iron in silicon and its impact on optimization of gettering
}

\author{
Peng Zhang, ${ }^{\text {a) }}$ Hele Väinölä, ${ }^{\text {b) }}$ Andrei A. Istratov, and Eicke R. Weber \\ Department of Materials Science and Engineering, University of California at Berkeley and Lawrence \\ Berkeley National Laboratory, MS 62R0203, 1 Cyclotron Road, Berkeley, California 94720
}

(Received 14 July 2003; accepted 2 October 2003)

\begin{abstract}
The redissolution behavior of gettered iron was studied in $p$-type Czochralski-grown silicon with a doping level of $2.5 \times 10^{14} \mathrm{~cm}^{-3}$ and an oxide precipitate density of $5 \times 10^{9} \mathrm{~cm}^{-3}$. The concentrations of interstitial iron and iron-boron pairs were measured by deep level transient spectroscopy. It was found that the dependence of redissolved iron concentration on annealing time can be fitted by the function $C(t)=C_{0}\left[1-\exp \left(-t / \tau_{\text {diss }}\right)\right]$, and the dissolution rate $\tau_{\text {diss }}^{-1}$ has an Arrhenius-type temperature dependence of $\tau_{\text {diss }}^{-1}=4.01 \times 10^{4} \times \exp \left[-(1.47 \pm 0.10) \mathrm{eV} / k_{B} T\right] \mathrm{s}^{-1}$. Based on this empirical equation, we predict how stable the gettered iron is during different annealing sequences and discuss implications for optimization of internal gettering. (C) 2003 American Institute of Physics. [DOI: 10.1063/1.1630158]
\end{abstract}

Iron is a ubiquitous and harmful metal impurity in silicon integrated circuit manufacturing. ${ }^{1,2}$ Gettering has been widely used in semiconductor processing ${ }^{3,4}$ to remove metal impurities from the device region. Among different gettering techniques, internal gettering ${ }^{5-7}$ of metals by oxide precipitates formed in the bulk of silicon wafers was shown to be very efficient for fast diffusers, such as iron. On the other hand, it was established that the gettered iron can redissolve into the silicon matrix if the wafer is reheated after gettering. Several groups have shown that the gettered iron can be completely dissolved within several minutes if the wafer is heated to a sufficiently high temperature. ${ }^{8-10}$ However, very little is known about the kinetics of this dissolution process, and whether there is a binding energy between the oxide precipitate and iron impurities which would slow down the dissolution of the gettered iron during short anneals at moderate temperatures, inherent in rapid thermal processing (RTP). In this letter, we report studies of the kinetics of the dissolution of iron precipitated at oxide precipitates in $p$-type Czochralski (CZ)-grown silicon as a function of temperature that allowed us to determine the effective barrier for the dissolution of the gettered iron. The experimental data are used together with gettering simulations to predict how the redissolution process affects the gettering stability during RTP.

The samples were prepared from $p$-type $200 \mathrm{~mm} \mathrm{CZ}$ silicon wafers with a boron doping level of 2.5 $\times 10^{14} \mathrm{~cm}^{-3}$ and initial oxygen concentration of 6.59 $\times 10^{17} \mathrm{~cm}^{-3}$. The wafer was first annealed at $1230^{\circ} \mathrm{C}$ to dissolve all oxygen clusters and then subjected to oxygen nucleation treatments at $650{ }^{\circ} \mathrm{C}$ for $14 \mathrm{~h}$ followed by $4 \mathrm{~h}$ $800^{\circ} \mathrm{C}$ and $16 \mathrm{~h} 1000{ }^{\circ} \mathrm{C}$ growth steps. Well-defined oxide precipitates, ${ }^{11}$ with a density of approximately 5 $\times 10^{9} \mathrm{~cm}^{-3}$ were obtained, which was confirmed by preferential etching and then counting the pits. Based on the density of the oxide precipitates and the decrease in interstitial

\footnotetext{
${ }^{a)}$ Electronic mail: pzhang@lbl.gov

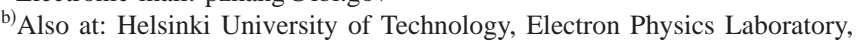
P.O. BOX 3500, FIN-02015 HUT, Finland.
}

oxygen concentration, assuming spherical $\mathrm{SiO}_{2}$ precipitates with oxygen atomic concentration of $C_{p}=4.6 \times 10^{22} \mathrm{~cm}^{-3}$, an average radius of an oxide precipitate was estimated to be $r \approx 88 \mathrm{~nm}$. The samples were intentionally contaminated by evaporating a thin film of iron on the back side of the sample, followed by a drive-in annealing of $50 \mathrm{~min}$ at $950{ }^{\circ} \mathrm{C}$ in an ambient of $96 \% \mathrm{~N}_{2}+4 \% \mathrm{H}_{2}$. After that, the set point of the furnace was changed to cool the samples to $700^{\circ} \mathrm{C}$. The average cooling rate of the furnace in this temperature range was measured to be approximately $14{ }^{\circ} \mathrm{C} / \mathrm{min}$. Then the samples were kept at $700^{\circ} \mathrm{C}$ for $30 \mathrm{~min}$, after which the temperature was decreased to $450{ }^{\circ} \mathrm{C}$ during the next $30 \mathrm{~min}$. This gettering anneal was terminated by quenching the samples to room temperature by dropping them on an aluminum plate. The gettering efficiency was tested by deep level transient spectroscopy (DLTS), which confirmed that no detectable concentration $\left(\sim 10^{10} \mathrm{~cm}^{-3}\right)$ of ungettered interstitial iron was left in the sample. After etching off approximately $50 \mu \mathrm{m}$ from the surface by a $\mathrm{HNO}_{3}+\mathrm{HF}+\mathrm{H}_{2} \mathrm{O}$ solution (performed to remove surface iron silicide), the samples were annealed at $750{ }^{\circ} \mathrm{C}, 800{ }^{\circ} \mathrm{C}, 850{ }^{\circ} \mathrm{C}$, or $900{ }^{\circ} \mathrm{C}$ for different times between several seconds and several minutes (dissolution annealing) in the same gas mixture as mentioned above. The dissolution annealing was terminated by quenching the samples on an aluminum plate. The top layer (about $100 \mu \mathrm{m}$ ) was chemically removed, after which the aluminum Schottky diodes were deposited by thermal evaporation, and DLTS analyses were performed to measure the dissolved iron concentration in the samples.

Figure 1 shows the typical result of dissolved iron concentration versus dissolution annealing time at $800^{\circ} \mathrm{C}$. The experimental data points were fitted with an exponential function: $\quad C(t)=C_{0}\left[1-\exp \left(-t / \tau_{\text {diss }}\right)\right], \quad$ where $\tau_{\text {diss }}=(198 \pm 83) \mathrm{s}$ and $C_{0}=4.58 \times 10^{12} \mathrm{~cm}^{-3}$; the solubility of iron in silicon at this temperature. ${ }^{1}$ Note that the dissolution time constant of $198 \mathrm{~s}$ at $800^{\circ} \mathrm{C}$, albeit short, is much greater than a prediction based on the assumption that there is no dissolution barrier, i.e., that the redissolve process is only limited by iron diffusivity and solubility in silicon and 


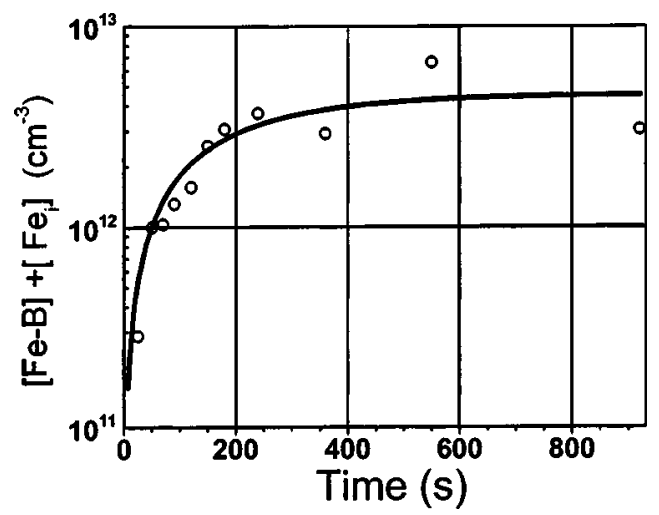

FIG. 1. The dependence of the dissolved iron concentration on annealing time at $T=800{ }^{\circ} \mathrm{C}$.

the time constant $\tau=1 /(4 \pi n r D)=2.53 \mathrm{~s}$. It has been previously shown ${ }^{12}$ that the effective iron density of the precipitate sites, obtained from iron precipitation kinetics using the same gettering temperatures and similar oxide precipitate density as in our experiments, is in a good agreement with the oxide precipitate density. Therefore, it is easy to show that if there were no dissolution barrier, the gettered iron would redissolve in less than $10 \mathrm{~s}$ at the annealing temperature of $800^{\circ} \mathrm{C}$ in $\mathrm{CZ}$ silicon with the density of the oxide precipitates as $5 \times 10^{9} \mathrm{~cm}^{-3}$, which corresponds to the interprecipitates distance $5.8 \mu \mathrm{m}$.

Measurements of the dependence of dissolution kinetics of precipitated iron on the annealing temperature (shown in Fig. 2) revealed an Arrhenius dependence of iron dissolution rate $\tau_{\text {diss }}^{-1}$ on annealing temperature $T$ :

$$
\tau_{\text {diss }}^{-1}=4.01 \times 10^{4} \times \exp \left(-E_{A} / k_{B} T\right) \mathrm{s}^{-1},
$$

with the effective energy barrier for iron dissolution of $E_{A}=(1.47 \pm 0.10) \mathrm{eV}$, significantly larger than the activation energy of $E_{D}=0.67 \mathrm{eV}$ (Ref. 1) for Fe diffusion in silicon. Hence, our data indicate that there is a substantial binding energy between gettered iron and oxide precipitates.

In the past, it was assumed that there is no barrier for iron dissolution except for its diffusion barrier, and therefore any heat treatment dissolves the gettered iron almost instantly. Hence, only the final cooling treatment was assumed to be important for the overall internal gettering efficiency and only this cooling had to be optimized. It is very likely that the dissolution barrier, reported in this letter, has little or no impact on the behavior of iron during furnace anneals

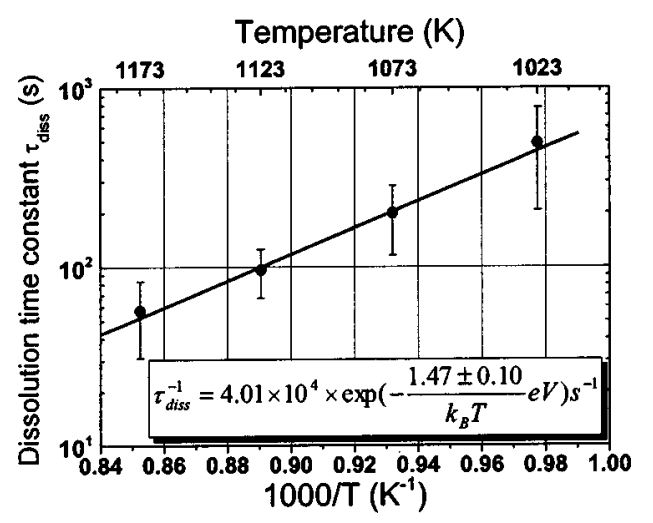

FIG. 2. Temperature dependence of the iron dissolution time constant.

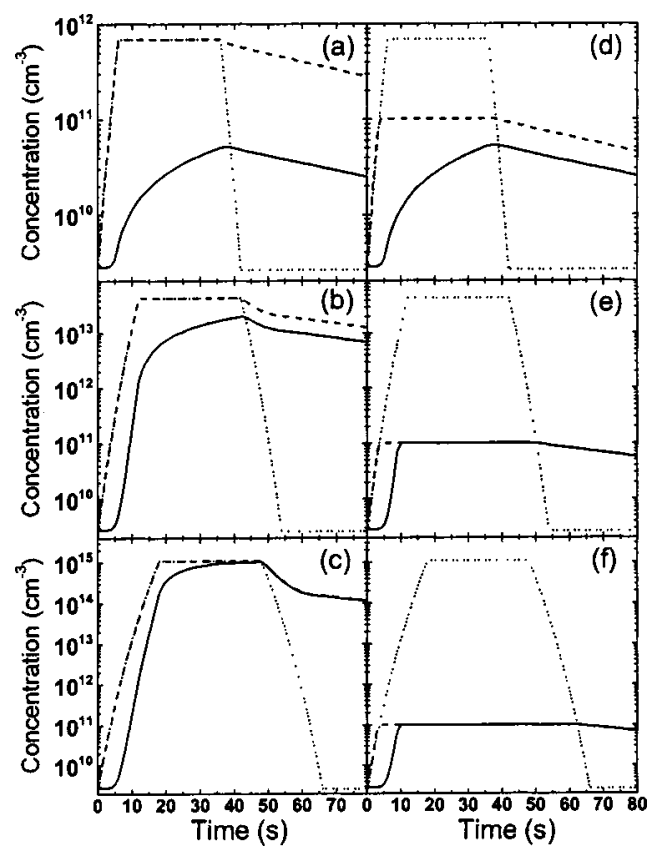

FIG. 3. Dissolved iron concentration during $30 \mathrm{~s}$ rapid thermal anneal at three different temperatures: (a) and (d) $750{ }^{\circ} \mathrm{C}$, (b) and (e) $900{ }^{\circ} \mathrm{C}$, and (c) and (f) $1050{ }^{\circ} \mathrm{C}$ simulated with (solid line) and without (dashed line) binding energy. The dotted line presents the equilibrium iron solubility during the annealing treatment.

with inherently slow temperature ramping rates. However, one may be able to take advantage of incomplete iron dissolution during RTP which often has rapid heating and cooling steps combined with a short processing time at moderate temperatures. In this case, gettering efficiency may be improved by optimizing not only the last cooling, but also all previous processing steps.

In order to address this problem, we used the experimental data obtained above to perform modeling of gettering and redissolution of iron during a sequence of rapid heating, followed by a short heat treatment and fast cooling, typical for RTP. The gettering simulator used in this study was based on the algorithm described in detail in Ref. 13, which uses Ham's law ${ }^{14}$ to describe diffusion-limited precipitation of iron. The dissolution process was described by the following equation:

$$
\begin{aligned}
C(t)= & C(t-\Delta t)+[S(t)-C(t-\Delta t)] \\
& \times\left[1-\exp \left(-\Delta t / \tau_{\text {diss }}\right)\right],
\end{aligned}
$$

where $C$ is the dissolved iron concentration, $S$ is the solubility, and $\tau_{\text {diss }}$ is given by Eq. (1).

Figure 3 shows examples of how iron is predicted to behave during a short RTA treatment at different temperatures with and without dissolution barrier. Two cases were modeled, corresponding to high and low iron contamination levels. In Figs. 3(a)-3(c), the amount of iron gettered at oxide precipitates is equal to or exceeds the equilibrium iron solubility at the processing temperature and the initial condition is that all the supersaturated iron impurities are gettered, i.e., the dissolved iron concentration equals the solubility at the starting temperature. The ramp rate is $25^{\circ} \mathrm{C} / \mathrm{s}$ from $600{ }^{\circ} \mathrm{C}$ to $750{ }^{\circ} \mathrm{C}-1100{ }^{\circ} \mathrm{C}$ and the length of the anneal time is $30 \mathrm{~s}$. In the simulations, the oxide precipitate density is set to $5 \times 10^{3} \mathrm{~cm}^{-3}$ and the precipitates are assumed to be 
homogeneously distributed throughout the wafer. It is seen in Fig. 3(a) that in the case of no barrier (dashed line), the dissolved iron closely follows the solubility (dotted line) and almost instantly reaches the level of $7 \times 10^{11} \mathrm{~cm}^{-3}$, whereas the dissolved iron concentration calculated with the dissolution barrier does not exceed $5 \times 10^{10} \mathrm{~cm}^{-3}$ by the end of the $750{ }^{\circ} \mathrm{C}, 30 \mathrm{~s}$ anneal. At $900^{\circ} \mathrm{C}$ [Fig. 3(b)], we can still detect some difference between the models but at $1050^{\circ} \mathrm{C}[\mathrm{Fig}$. $3(\mathrm{c})]$ after $10 \mathrm{~s}$ anneal, the dissolved iron concentration already reaches the solubility even in the presence of the dissolution barrier. Hence, in laboratory experiments which frequently use relatively high iron contamination levels, the dissolution barrier has a significant impact on the total dissolved iron concentration observed after the anneal.

Figures 3(d)-3(f) illustrate the contamination level typical for a production line, where iron concentration does not exceed $10^{11} \mathrm{~cm}^{-3}$. In this set of simulations, the total iron concentration in the sample is set to be $1 \times 10^{11} \mathrm{~cm}^{-3}$. The initial condition and ramping profiles were the same as in Figs. 3(a)-3(c). As we can see from Fig. 3(d), with the consideration of dissolution barrier, the iron concentration does not saturate after RTP treatment at $750^{\circ} \mathrm{C}$. At a higher temperature, for example, $900{ }^{\circ} \mathrm{C}\left[\right.$ Fig. 3(e)] and $1050^{\circ} \mathrm{C}[$ Fig. $3(\mathrm{f})]$, the interstitial iron concentration reaches 1 $\times 10^{11} \mathrm{~cm}^{-3}$ (i.e., the precipitated iron dissolves completely) already during the temperature ramping. Thus, at high-temperature annealing and low iron contamination levels, the existence of the dissolution barrier has little or no impact on optimizing the gettering procedure.

In conclusion, the analysis of the dissolution kinetics of iron gettered by oxide precipitates in $\mathrm{Cz}$ silicon revealed that there is a strong binding between the gettered iron and oxide precipitates. The effective dissolution energy barrier was determined to be $E_{A}=(1.47 \pm 0.10) \mathrm{eV}$, as determined in the temperature range from $750{ }^{\circ} \mathrm{C}$ to $900{ }^{\circ} \mathrm{C}$. Considering the diffusion barrier of $0.67 \mathrm{eV}$ for iron diffusion in silicon, our results give an effective binding energy of $0.80 \mathrm{eV}$ between oxide precipitates and the gettered iron impurities. The nature of this barrier is not clear. It is not likely that the effective binding energy of $0.80 \mathrm{eV}$ is the result of retardation of diffusion by iron-boron paring similar to the effect of $\mathrm{CuB}$ pairing on copper diffusivity. ${ }^{15}$ This is because iron-boron pairs dissociate already at $200{ }^{\circ} \mathrm{C}$, whereas our dissolution experiments were performed at much higher temperatures, from $750{ }^{\circ} \mathrm{C}$ to $900^{\circ} \mathrm{C}$. At these temperatures and with boron doping level as low as $10^{14} \mathrm{~cm}^{-3}$, not only would FeB pairs dissociate instantly, but even their formation is unlikely since interstitial iron is predominantly neutral in $p^{-}$silicon at these temperatures. Additionally, precipitation kinetics of iron can be accurately described by Ham's law without any additional diffusion barrier. Hence, we conclude that the barrier stems from the microscopic interaction of iron with oxide precipitates. Additional studies are in progress to understand the nature of this interaction. The existence of this binding energy may be used to improve the efficiency of internal gettering during rapid thermal annealing, particularly at temperatures below $800^{\circ} \mathrm{C}$ or at high iron contamination levels. Our simulations demonstrated that short RTP anneals at moderate temperatures dissolve only a small fraction of the gettered iron.

The authors acknowledge the support by SiWEDS. One of the authors (H.V.) acknowledges support by Finnish National Technology Agency, Academy of Finland, Okmetic Oyj, Micro Analog Systems Oy, and VTI Technologies Oy. The authors are grateful to Dr. R. Falster from MEMC for providing the silicon wafers.

${ }^{1}$ A. A. Istratov, H. Hieslmair, and E. R. Weber, Appl. Phys. A: Mater. Sci. Process. 69, 13 (1999).

${ }^{2}$ A. A. Istratov, H. Hieslmair, and E. R. Weber, Appl. Phys. A: Mater. Sci. Process. 70, 489 (2000)

${ }^{3}$ S. M. Myers, M. Seibt, and W. Schröter, J. Appl. Phys. 88, 3795 (2000).

${ }^{4}$ A. A. Istratov, H. Hieslmair, and E. R. Weber, MRS Bull. 25, 33 (2000).

${ }^{5}$ T. Y. Tan, E. E. Garnder, and W. K. Tice, Appl. Phys. Lett. 30, 175 (1977).

${ }^{6}$ D. Gilles, E. R. Weber, and S. K. Hahn, Phys. Rev. Lett. 64, 196 (1990).

${ }^{7}$ M. Aoki, A. Hara, and A. Ohsawa, J. Appl. Phys. 72, 895 (1992).

${ }^{8}$ E. G. Colas and E. R. Weber, Appl. Phys. Lett. 48, 1371 (1986).

${ }^{9}$ M. Aoki and A. Hara, J. Appl. Phys. 74, 1440 (1993).

${ }^{10}$ S. A. McHugo, E. R. Weber, M. Mizuno, and F. G. Kirscht, Appl. Phys. Lett. 66, 2840 (1995).

${ }^{11}$ K. F. Kelton, R. Falster, D. Gambaro, M. Olma, M. Cornara, and P. F. Wei, J. Appl. Phys. 85, 8097 (1999).

${ }^{12}$ H. Hieslmair, A. A. Istratov, S. A. McHugo, C. Flink, T. Heiser, and E. R. Weber, Appl. Phys. Lett. 72, 1460 (1998).

${ }^{13}$ H. Hieslmair, S. Balasubramanian, A. A. Istratov, and E. R. Weber, Semicond. Sci. Technol. 15, 567 (2001).

${ }^{14}$ F. S. Ham, J. Phys. Chem. Solids 6, 335 (1958).

${ }^{15}$ A. A. Istratov, C. Flink, H. Hieslmair, E. R. Weber, and T. Heiser, Phys. Rev. Lett. 81, 1243 (1998). 